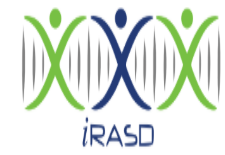

iRASD Journal of Management

Volume 3, Number 3, 2021, Pages 302 - 309

Journal Homepage:

https://journals.internationalrasd.org/index.php/jom

\title{
Do Bosses Get Bullied Too? A Qualitative Investigation of Causes, Impacts, and Treatments of Upward Workplace Bullying
}

\author{
Dr. Muhamad Farooq Rehan ${ }^{1}$, Dr. Quaisar Ijaz Khan², Dr. Raheel Mumtaz ${ }^{3}$ \\ ${ }^{1}$ Assistant Professor, College of Commerce, Government College University, Faisalabad, Pakistan. \\ ${ }^{2}$ Assistant Professor, College of Commerce, Government College University, Faisalabad, Pakistan. \\ ${ }^{3}$ Assistant Professor, College of Commerce, Government College University, Faisalabad, Pakistan. \\ Email: raheelmumtaz@gcuf.edu.pk
}

\section{ARTICLE INFO}

Article History:

Received:

Revised:

Accepted:

November 12, 2021

December 28, 2021

December 28, 2021

Available Online: December 29, 2021

\section{Keywords:}

Workplace bullying

Job description

Organizational culture

Conflict, Job rotation

Qualitative perspective

\section{ABSTRACT}

Workplace bullying is an emerging problem in the organizational setting, that if not properly managed can deteriorate the normal functioning of an organization and consequently may harm the achievements of organizational goals. Aim of this research study is to explore the causes, impacts, and treatments of upward workplace bullying where subordinate behave in an inhumane way against supervisor. Data was collected by using semi-structured interviews with 10 persons employed at senior supervisory levels in the city of Faisalabad, Pakistan. A thematic analysis indicates that unclear managerial boundaries, absurd job descriptions, and weak interpersonal skills of the employees are the major causes of upward bullying. Individual impacts of bullying on the aggrieved parties and organizational treatments to mitigate and control the phenomenon are discussed.

(c) 2021 The Authors, Published by iRASD. This is an Open Access article under the Creative Common Attribution Non-Commercial 4.0

OPEN

ACCESS

Corresponding Author's Email: raheelmumtaz@gcuf.edu.pk

\section{Introduction}

Bullying of any type is considered unethical whether it is at school or in the society or at workplace. Mostly, the target of bullying are less powerful individuals and they are targeted by the powerful individuals (Patterson, Branch, Barker, \& Ramsay, 2018). At work settings this inequality viewed as seniors with some authority bully their subordinates. Therefore, this term workplace bullying is mistreatment lower staff by their seniors, although this an unethical but considered common phenomenon at work setting. Workplace bullying is a recently observed phenomenon at all organizational levels (Kalliath \& Kalliath, 2012; Zapf \& Einarsen, 2003). It typically flows in a downward direction where a hierarically superior tries to influence subordinate (Schat, Frone, \& Kelloway, 2006). However, in few decades a type of workplace bullying is witnessed in an organizational setting where managers are dealt in an inappropriate way by the subordinate (Salin, 2001). This upward bulling is not new at the work setting (Bolling, 2019). Extent literature is truly evident of acknowledging the complexity, importance, and deteriorating impacts of upward workplace bullying (Sara Branch, Ramsay, \& Barker, 2013; Shallcross, Ramsay, \& Barker, 2010). Upward bullying is a gradual process where a staff member gains enough power to respond in an unethical way. This power is gained through an informal structural process which is developed through interpersonal communications with members from within or outside the organization. Sara Branch, Ramsay, and Barker (2007) stated that imbalance of power is a perpetual cause of upward bullying. Although we found evidence from the literature concerning the causes and impacts of workplace bullying, little is known as to how the organizations have taken measures for controlling the occurrences of future incidences. 
Causes, impacts, and countermeasures or treatments of workplace bullying is primarily a function of organization type, the culture from where the organizational personals belong, and the aptitude of management towards these incidences. Therefore, a study is conducted to bridge this gap specifically in the context of a developing country. Data is collected through semi-structured interviews with ten participants who worked at managerial and supervisor level. Participants are selected on the basis of theirs being a victim or witness of upward bullying incidences. Thematic analysis is performed to understand the contents of data and findings highlighted that blurred boundaries of managerial positions, weak interpersonal skills of managers, ambiguous job descriptions, and machiavellianistic managerial attitude create pressures on the accused parties. These incidences put pressure on both the parties. Anxiety, sudden burst, or sometimes silence in the communication is witnessed as a consequential response to upward bullying. Job rotation is found to be the most prevailing countermeasure that organizations usually take to counter measure these sorts of incidents.

Several studies in the literature highlighted the causes of workplace bullying e.g. (Einarsen, Hoel, Zapf, \& Cooper, 2020) specifically dealing with the typical, most inspected, and usual form of downward workplace bullying (Wallace, Johnston, \& Trenberth, 2010; Yagil, 2006). Legitimate power, expert power, informational power, and reward power can enable a manager to exercise the bullying tactics to get the work done by his subordinates (French, Raven, \& Cartwright, 1959).

These power attributes (Keashly \& Jagatic, 2010) can be skewed towards lower positional end and can place a staff member in a position to retaliate against supervisor or manager, thus causing upward workplace bullying (Shallcross et al., 2010), Few studies are found in the literature that have explored this issue in a close-ended way i.e. through questionnaires (Wallace et al., 2010). Therefore, timely research is required to explore the subject phenomenon in an open-ended style that can highlight the causes, impacts, and counter-measures linked with upward workplace bullying.

\section{Literature Review and Research Objective Development}

Organizations are social entities that are directed towards achievements of commonly defined goals. Business organizations are composed of people who interact with each other in a regular while performing their duties. These interactions and the hierarchal divisions make sure the design and execution of communication protocols that are to be followed by the entities at the individual, group, and organization level. In the meanwhile, organizations must interact with its external environment where stakeholders can influence their role in defining the success or failure as associated with the specific entity (Daft, 2015).

Workplace bullying is defined in the literature through a multitude of behaviors and tactics. These behaviors may include intimidation, aggressive actions, harassment, or violent actions, intentional withdrawal of information from a specific individual or group, frequent questioning the abilities of a person, and behaving in an unethical style. Einarsen et al. (2020) stated three conditional features of workplace bullying behavior. Firstly, the behavior is inappropriate, inhumane, and unreasonable (Sara Branch et al., 2013; Hershcovis, 2011; Wallace et al., 2010). Workplace bullying can include overt or covert behaviors. e.g. frequently and unnecessarily questioning the others abilities, intentionally excluding someone from the relevant tasks, constantly inspecting an individual's tasks, doing physical harm, spreading rumors, withholding information, unraveling the explosive outbursts, and ridiculing others (Zapf \& Einarsen, 2001).

Secondly, the behavior must be repeated regularly, as a standalone behavior cannot be termed as bullying behavior (Sara Branch et al., 2013). Therefore, we can say that a bullying episode may be a result of several bullying incidences. Lastly, a power imbalance must be present between the two parties. Power as associated with a particular's position, either formal or informal, can work in a complicated way to frame the culture of an organization. The employees in an organization can depart from the formal power structure, thus causing the workplace bullying. A mere conflict of ideas between two persons linked with each other at a same power nexus cannot be called a bullying behavior. A power 
imbalance may result through formal sources, that might include (a) keeping a distinguishing information relevant to a specific task, (b) a special professional ability that make an individual superior over others. Informal sources of power imbalance may include making links with a special power group within and outside the organizations. These power imbalances can enable the superior party to exploit the differentiating skills and cause the incidences of workplace bullying (Keashly \& Jagatic, 2010).

Upward workplace bullying covers all indecent overt and covert behaviors exhibited by staff members to the managers. An accused person of upward bullying may get enough power through formal and informal routes that can place him in a position to exploit the dependency of his managers, informational and skill differentials as linked with the position of a staff member.

Abusive supervision can create a chronic stress for the subordinate that either terminate the relationships or change the relationship according to the prevailing conditions. One type of the contemporary modification may be the workplace bullying by the subordinate, supervisor or both the parties (Tepper, 2000). Tepper, Duffy, and Shaw (2001) state that staff members express their resentments against abusive supervision by resisting the downward influence attempts by the supervisor. Unattractive communication style as exercised by the manager may indulge subordinates to behave in a domineering and contentious way (Garko, 1994).

Current work environment, power imbalances, and a change process in the organization may cause upward workplace bullying (Sara Branch et al., 2007). Yet another cause of upward workplace bullying is the exploitation of the legislative rules where the staff member is reporting the legitimate power of his supervisor as a suppressive act (Wallace et al., 2010). Bricks et al., (2014) noted that perpetrators of upward workplace bullying may gain power through external organizations so that they can exert pressure on the managers against his legitimate enforcing behaviors. Dependency is another major cause of upward workplace bullying where a staff exploit his position to demean the routine working environment.

Upward workplace bullying can cause depersonalization, reduction in the perceived personal accomplishment, and emotional exhaustion for the supervisor (Patterson et al., 2018). Jenkins, Winefield, and Sarris (2011) describe that managers who were victim of upward workplace bullying suffered from emotional distress. These managers usually apply for sick leaves as a consequent of workplace bullying episodes. Managers who faced upward workplace bullying reported that they suffered from general ill health issues, anxiety, migraine, high perceptions of stress, shingles, and sleeplessness (Sarah Branch, 2006).

Based on the above discussion, It is evident that literature has discussed a variety of causes and impacts of upward workplace bullying. As for as the counter-measures of upward workplace bullying is concerned no evidence is found that had discussed it with detail. A possible reason for this gap may be the non-generalizability of the recommendations. As this entire process of causes, impacts, and counter-measures of upward workplace bullying is a function of organization type, individual personality type, and perceived levels of tolerance of both the parties. Therefore, a qualitative research based on the open-ended question can provide insights into the matter.

Following research objectives are designed to explore the matter in detail.

Obj1: To explore the causes of upward work place bullying in industries in Faisalabad, Pakistan.

Obj2: To highlight the impacts of upward workplace bullying on the aggrieved party, accused party, at the individual level and the organization at the macro level.

Obj3: To sort out the actions an organization can devised to limit the frequency of these incidences, or to mitigate the influence of these actions. 


\section{Methodology}

As we have already discussed the subjective nature of the phenomenon of upward workplace bullying, we conducted semi-structured interviews with the victimized and witnessing individuals of upward workplace bullying behavior. Gibson and Brown (2009) described the relevance and appropriateness of thematic analysis to examine the relationships between different concepts in the text data. Therefore, thematic analysis framework is adopted to conceptualize the findings from transcribed data. Participant selection is based on several conditions. For example, a person who is a victim of upward workplace bullying can answer the questions relating to the "causes and impacts" in a better way as compared to the questions relating to the "counter-measures". Therefore, the portfolio of participants includes both the victim and witnessing individuals of upward workplace bullying. As for as the selection of witnessing individual is concerned, we made two conditions criteria that either respondent is the only individual who is in a position to witness all incidences of upward workplace bullying or he is in the position to devise a policy to counter measure these incidences. If any one condition is fulfilled, that individual is targeted for recruitment. We adopted a snow ball sampling technique to make a list of the relevant individuals. Based on the above criteria, we contacted fourteen individuals who were victim of upward workplace bullying and six individuals who were fulfilling the criteria of a witnessing person. To get a lively and true depiction of the original incidences, we limit the selection to the individuals who had experienced the said phenomenon during the last two years. we obtained consent of the participants through an e-mail clearly highlighting the interview protocols and secrecy protocols. Eleven participants were agreed to respond, one of the participants (a witness) was not interviewed because of his non-availability. As the nature of the questioning was sensitive to the personality of a manager, we were not permitted to record voices of the interviewees, rather we took notes for all interviews against all questions. To validate my notes, we read the writings from our notes before the participants to confirm their sayings. Later-on, a content analysis is conducted to analyses the data. Table 1 list the demographics of all participants of the study. To better understand the findings in relation to the research questions, we divided the finding section in three categories each representing a separate research question. These sub divisions are further distributed into different themes.

\section{Table 1}

Demographics of the Participants

\begin{tabular}{|c|c|c|c|c|c|}
\hline $\begin{array}{l}\text { Participant } \\
\text { Name }\end{array}$ & Gender & $\begin{array}{l}\text { Managerial } \\
\text { Level }\end{array}$ & $\begin{array}{l}\text { Industry } \\
\text { Type }\end{array}$ & $\begin{array}{l}\text { Job } \\
\text { Experience }\end{array}$ & Victim/Witnessed \\
\hline Participant 1 & Male & $\begin{array}{l}\text { Senior service } \\
\text { Manager }\end{array}$ & Automobile & $>10$ years & Victim \\
\hline Participant 2 & Male & Foreman & Automobile & $>10$ years & Witnessed \\
\hline Participant 3 & Male & Account Manager & Textile & $\begin{array}{l}5 \text { years > } \\
\text { Experience < } \\
10 \text { years }\end{array}$ & Victim \\
\hline Participant 4 & Male & $\begin{array}{l}\text { Manager } \\
\text { Operations }\end{array}$ & Paints & $>10$ Years & Victim \\
\hline Participant 5 & Male & Manager Sales & Paints & $>10$ Years & Victim \\
\hline Participant 6 & Male & $\begin{array}{l}\text { Manager } \\
\text { Recovery }\end{array}$ & Chemical & $\begin{array}{l}5 \text { years > } \\
\text { Experience < } \\
10 \text { years }\end{array}$ & Witness \\
\hline Participant 7 & Female & $\begin{array}{l}\text { Business Relation } \\
\text { Officer }\end{array}$ & Banking & $<5$ Years & Witness \\
\hline Participant 8 & Male & In charge & Education & $>10$ Years & Victim \\
\hline Participant 9 & Male & General Manager & Services & $>10$ Years & Witness \\
\hline $\begin{array}{l}\text { Participant } \\
10\end{array}$ & Male & Director & Education & $>10$ Years & Victim \\
\hline
\end{tabular}

\subsection{Causes of Upward Workplace Bullying}

Content analysis of the field notes help me identify several key causes of the phenomenon. In this study themes have been arranged according to their repetition. In the following passage, themes are discussed with supporting arguments as presented by the participants. 


\section{Blurred Boundaries of Managerial Positions}

Participants told us that in their organization, organograms are structured for a mere formality. A less formal consideration is paid to the implement of these structure. This less emphasized implementation creates a clash between the stated and actual situation. For example, one of the participants (participant 6) mentioned that;

"...in my organization, people are often confused as to whom to respond in case of problem. It is not the case that we do not know the documents, but the reality is in strict contrast to that .... management never took seriously the implementation of these bookish documents."

These informal organizational cultures create the absence of unity of the command. People are routinely confused; they are pressurized from multiple persons to achieve the targets. This creates anxiety on the part of a staff member. One of the participants had even justified the bullying behavior of a staff member. For example, participant 6 told me further that;

"If I was at his position, I might have retaliated in the same way. In-fact when we are bombarded from several bosses, ... Mr. XYZ (Actual Name is not mentioned here) have absorbed the pressure for several months. He was humiliated on the failures, even though these failures were a result of confusion in understanding the problem situation. He was found frustrated all the time during work hours. No one will re-call the reasons..." weak interpersonal skills of managers

A weak Behavior-Situation synchronization may cause the staff and managers to respond without understanding the facts. Highlighting the mistakes of a dedicated staff member may not only discourage him but also instigate him to retaliate in an outburst way. Taken for example, participant 1 said,

"I was routinely managing the situation; he was not supposed to behave in that way. Although he is a good worker, but he was not concentrating on his tasks for couple of weeks... that offend me to behave like that. He started shouting at me, and I was surprised and hurt at his attitude." ambiguous job descriptions.

This theme is concluded from the responses of participants who belong to the small organizations where job responsibilities are verbally communicated. People of these organizations starts avoiding to take new responsibilities, they start exaggerating the level of difficulties as associated with the new projects. Thus, they start creating an environment where dis-allowing the saying of their managers is considered a norm. Participant 4 has expressed the situation in the following manner.

"Being a manager, I am responsible to get work from my subordinates. He was explained at the time of job placement to follow my instructions. I referred to that explanation repeatedly.... he started retaliation, he shouted at me, and physically abused me... he must not do that in any situation"

\section{Machiavellianism Approach}

A Machiavellian managerial approach is found to be a cause of upward bullying, where managers are routinely setting the targets without providing the required resources. In these situations, a staff member usually fails to differentiate between ineffectiveness and incompetence. Consistent directional approach by the management insist the employees to behave inappropriately.

Lack of education is also found to be a cause of upward bullying but we excluded this from our discussion because the level of education is a function of size of an organization. A small organization will hire less experienced and less educated staff. This lack of education levels prevails in the overall organization, thus eliminating the marginal differences in the expectations and behaviors. 


\section{Impacts of Upward Workplace Bullying}

Analysis of the field notes indicated three major impacts of workplace upward bullying on the accused party. We aggregated the codes and arrange these themes in the order of frequency.

Three out of four witnesses stated that managers who faced upward bullying get use to different kinds of unpredictable behaviors. These behaviors emerged soon after the bullying episodes. These behaviors include (a) increase in smoking, (b) late sitting in the office aimlessly, (c) speaking in an overly conscious way that could not be considered a usual way, (d) decrease in socializing with colleagues, and (e) taking frequent casual leaves. According to a participant,

"Mr. ABC was so depressed that we all in the office clearly observed a change in the way he was used to do work in the office. He started behaving reserved and in overly conscious way, he stopped relaxing people for their routine adjustments. He became more formal in a way that was actually unprecedented by him... he was not a person of that kind."

Other participants said;

"No one can even imagine that he will take the problem so serious. He went on leave for consecutive three days without any strong personal reason. He silenced his phone and did not respond to anyone... things on his part were changed dramatically."

Still another participant stated that;

"Although he (manager) was very tough at the job, but the behavior of that staff member (accused) really left him blank. He was badly suffered, he started avoiding that individual. He limits the interaction with people especially with that specific group to which that staff member (the accused) belongs."

Content analysis emphasized two major type of responses, either the manager started shouting over the accused immediately, or remained silent. The contents described that these two types of behaviors come in the transition sometime as one preceding the other. For example, one of the participants who was an eye witness of upward bullying explained the behavior of victim by saying that

"At once the boss actually remained silent. He faced the situation calmly. ... But after that incident, boss started questioning the abilities of the accused. A special behavior was shown to the accused and that was really unpredictable because the immediate response of the boss was really very calm."

\section{Counter-measures of Upward Workplace Bullying}

Responses from the participants indicated that counter-measures of upward workplace bullying was a function of post-incident behavior of both the parties. We reanalyzed the contents to understand the link between behaviors and counter-measures and found that a silenced behavior from manager mitigate the severity of the situation. Taken for example, Participant 7 explained the post incident situation as follow;

"Manager took the situation so wisely, although being on the right side, she remained silent, she limits interaction with that individual... After three or four days the accused submit a letter of pardon to that manager."

However, there should be proper systems, that deals with the upward bulling and grievances management systems should also be reviewed by the higher management in order to avoid abuse of the system. While explaining the post incident situation, one of the participant explained; 
"Organization should launch grievances management systems in order to deal with the both type of bulling, and I believe that this system should be periodically reviewed by the stakeholders, so that the system could not be misused."

\section{Conclusion, Limitations, and Future Research Directions}

This research is conducted with a primary focus on understanding the causes, impacts, and countermeasures related to the upward workplace bullying. Semi-structures interviews with 10 participants at various organizational levels are conducted. Thematic analysis of the interview contents highlighted that majority of the causes of workplace bullying relate with the inadequate planning by the higher management. The study observed from these interviews that both victims and witnesses are of the opinion that an equity-based system in the organization can solve the problem. Higher management should take their responsibility in cultivating an environment. Higher management should ensure that (a) jobs are properly designed, (b) organizational structures are truly documented as well as implemented, and (c) an effective system of evaluating the causes of workplace bullying is designed. Workplace bullying is detrimental for the smooth functioning of an organization. It can create physical, emotional, and psychological impacts on the accused party. Furthermore, Walker and Stones (2020) are also of the view that workplace bulling not only having negative impact on mental disorder but it has negative effect on the organizational culture. Responsible management should take effective counter-measures to mitigate the effects of workplace bullying like launching of grievance management system at organizational level and in order to reduce the risk of abuse of the system, this system should be reviewed continuously (Sara Branch, Ramsay, Shallcross, Hedges, \& Barker, 2018). Moreover, it is also suggested to implement employee mental health management system as suggested by Chen, Tai, and Chu (2021), by implementing this system supervisor level employee will be able to deal with their stress and anxiety related issues (Chen et al., 2021).

Despite the in-depth analysis of workplace situations, this research is not without limitations. Firstly, this study focuses only on the participants from one city. These participants represent a specific culture, values, and reactions from the perspective of only one city. These variables may change from one city to another, and more importantly across different countries. Therefore, a more detailed study can be conducted with a large sample of the participants. Secondly, a mixed-methods approach can tradeoff the demerits associated with both the qualitative as well as quantitative techniques. A scale for measuring the causes, and impacts may be developed and later the data can be collected from a relatively large sample. Thirdly, due to the time constraint, stance of the accused party is not included in the study. Future studies may be conducted to include the views from both the parties.

\section{References}

Bolling, J. A. (2019). Upward Bullying in the Workplace: A Phenomenological Study. eJournal of Social \& Behavioural Research in Business, 10(1), 61-77.

Branch, S. (2006). Upwards bullying: An exploratory study of power, dependency and the work environment for Australian managers. (Doctoral Thesis), Griffith University, Brisbane,

Branch, S., Ramsay, S., \& Barker, M. (2007). Managers in the firing line: Contributing factors to workplace bullying by staff-an interview study. Journal of management \& organization, 13(3), 264-281. doi:https://doi.org/10.5172/jmo.2007.13.3.264

Branch, S., Ramsay, S., \& Barker, M. (2013). Workplace bullying, mobbing and general harassment: A review. International Journal of Management Reviews, 15(3), 280299. doi:https://doi.org/10.1111/j.1468-2370.2012.00339.x

Branch, S., Ramsay, S., Shallcross, L., Hedges, A., \& Barker, M. (2018). Bosses get bullied too: exploring upwards bullying to learn more about workplace bullying. Pathways of Job-related Negative Behaviour, 1-32. doi:https://doi.org/10.1007/978-981-106173-8 11-1

Chen, Y.-C., Tai, H.-J., \& Chu, H.-C. (2021). Constructing Employee Assistance Program Measures Against Workplace Bullying. Employee Responsibilities and Rights Journal, 1-21. doi:https://doi.org/10.1007/s10672-021-09394-y

Daft, R. L. (2015). Organization theory and design: Cengage learning. 
Einarsen, S. V., Hoel, H., Zapf, D., \& Cooper, C. L. (2020). The concept of bullying and harassment at work: The European tradition. In Bullying and harassment in the workplace (pp. 3-53): CRC press.

French, J. R., Raven, B., \& Cartwright, D. (1959). The bases of social power. Classics of organization theory, 7, 311-320.

Garko, M. G. (1994). Communicator styles of powerful physician-executives in upwardinfluence situations. Health Communication, 6(2), 159-172. doi:https://doi.org/10.1207/s15327027hc0602 5

Gibson, W., \& Brown, A. (2009). Working with qualitative data: Sage.

Hershcovis, M. S. (2011). "Incivility, social undermining, bullying... oh my!": A call to reconcile constructs within workplace aggression research. Journal of organizational behavior, 32(3), 499-519. doi:https://doi.org/10.1002/job.689

Jenkins, M., Winefield, H., \& Sarris, A. (2011). Consequences of being accused of workplace bullying: an exploratory study. International Journal of Workplace Health Management, 4(1), 33-47. doi:https://doi.org/10.1108/17538351111118581

Kalliath, T., \& Kalliath, P. (2012). Changing work environments and employee wellbeing: an introduction. International Journal of Manpower, 33(7), 729-737. doi:https://doi.org/10.1108/01437721211268285

Keashly, L., \& Jagatic, K. (2010). North American perspectives on workplace hostility and bullying. S. Einarsen, $H$. Hoel, \& D. Zapf. Bullying and harassment in the workplace: Developments in theory, research and practice 2nd Edition, 41-71.

Patterson, E., Branch, S., Barker, M., \& Ramsay, S. (2018). Playing with power: Examinations of types of power used by staff members in workplace bullying-A qualitative interview study. Qualitative Research in Organizations and Management: An International Journal, 13(1), 32-52. doi:https://doi.org/10.1108/QROM-10-20161441

Salin, D. (2001). Prevalence and forms of bullying among business professionals: A comparison of two different strategies for measuring bullying. European journal of work and organizational psychology, 10(4), 425-441. doi:https://doi.org/10.1080/13594320143000771

Schat, A. C., Frone, M. R., \& Kelloway, E. K. (2006). Prevalence of Workplace Aggression in the US Workforce: Findings From a National Study. doi:https://doi.org/10.4135/9781412976947.n4

Shallcross, L., Ramsay, S., \& Barker, M. (2010). A proactive response to the mobbing problem: a guide for HR managers. New Zealand Journal of Human Resources Management, 10(1), 27-37.

Tepper, B. J. (2000). Consequences of abusive supervision. Academy of management journal, 43(2), 178-190. doi:https://doi.org/10.5465/1556375

Tepper, B. J., Duffy, M. K., \& Shaw, J. D. (2001). Personality moderators of the relationship between abusive supervision and subordinates' resistance. Journal of applied psychology, 86(5), 974-983. doi:https://doi.org/10.1037/0021-9010.86.5.974

Walker, J., \& Stones, A. (2020). Impact of Workplace Bullying Amongst First RespondersSystematic Review. International Journal of Psychological Research and Reviews, 3, 24-24.

Wallace, B., Johnston, L., \& Trenberth, L. (2010). Bullying the boss: The prevalence of upward bullying behaviours. The Australasian Journal of Organisational Psychology, 3(1), 66-71. doi: https://doi.org/10.1375/ajop.3.1.66

Yagil, D. (2006). The relationship of abusive and supportive workplace supervision to employee burnout and upward influence tactics. Journal of emotional abuse, 6(1), 49-65. doi:https://doi.org/10.1300/J135v06n01 03

Zapf, D., \& Einarsen, S. (2001). Bullying in the workplace: Recent trends in research and practice - an introduction. European journal of work and organizational psychology, 10(4), 369-373. doi:https://doi.org/10.1080/13594320143000807

Zapf, D., \& Einarsen, S. (2003). Individual antecedents of bullying: Victims and perpetrators. 